\title{
Restructuring Out of Recession
}

\section{Richard Jolly}

It is paradoxical that the industrialised countries, most of which are not using their production potential to the full, are hesitating to increase their financial aid to poor countries. This is despite the fact that such aid could result in increased global demand and thus contribute to reactivation of world trade in a recovery of production. There is nothing in the present state of deflationary chain reactions in the industrialised world, stagnation feeding inflation, which would argue against such an increase in financial aid.

This impressive call for action was given by no less than M. de Larosière, Managing Director of the IMF, speaking at UNCTAD $V$ in Manila. Since March, with no easing of stagflation in spite of heavy doses of monetarist medicine in many countries, the world economy has moved closer to recession. Aid transfers are being restrained-and sometimes cut-and other financial flows are increasingly put in jeopardy by fears of mounting debt.

In fact, a consensus resolution was reached on these matters at UNCTAD V, in the committee on the transfer of real resources. Amongst other points, this stated that substantially increased transfers of resources to developing countries are an indispensable factor for accelerating their pace of development and could help stimulate global economic activity, particularly in a medium to long-term perspective. The committee noted that several approaches, including co-financing with private resources, could usefully be combined in order substantially to increase transfers of resources, largely raised on the financial markets and without prejudice to official development assistance.

Unfortunately it seems that this proposal is not being given the serious attention it deserves in spite of clear evidence of the size of the impact it could make on levels of economic activity in both developed and developing countries. Policy makers and analysts are cautious-in part through genuine uncertainties but in part, one suspects, because interaction with developing countries is still considered primarily a political/ diplomatic matter, not one of fundamental importance for the health of the world economy as a whole, let alone for the levels of employment, economic activity and growth within the developed countries themselves. Yet the facts speak otherwise.

Over the last few years, a major recycling of financial surpluses to developing countries has in fact sustained economic activity in the developed countries and held the line against further deterioration in respect of unemployment, underutilisation of capacity and even inflation. The EEC, for example, estimates that there would be $3 \mathrm{mn}$ more unemployed if the non-oil developing countries had cut their manufactured imports to meet the increased oil prices of 1973-74 rather than borrowing to maintain their level. By borrowing, their purchasing power has risen to account for 25 per cent of US exports and 20 per cent of EEC exports. As a result trade in manufactured goods with the newly industrialising countries alone has been found by the OECD to have created an average net gain of 900,000 jobs for the developed economies in each of the years 1973-77.

Nevertheless, the likelihood of this process continuing is far from certain. The Community Annual Economic Review 1978-79 summarised the position as follows:

The present equilibrium of the world economy-depends to a considerable degree on a continuing flow of private lending to the non-oil producing developing countries (and to Soviet Union and Eastern Europe) on a scale unheard of before 1974 and would be called in question by any impediment to that flow.

(CEC 1978, section 8)

It is against this wider background that the world economy is now being called upon to adjust to a further increase in the price of oil. It is far from clear that the same recycling mechanisms will be able to operate for a further five years, starting as they do this time with the structure of international debt already considerably extended. The total outstanding debt of developing countries at the end of 1979 will already be some $\$ 300$ bn -and current account deficits of non-oil developing countries in this year alone are estimated to reach a new peak of at least $\$ 50 \mathrm{bn}$. This deficit could be met by increased exports and/or increased financial transfers-or it could 
lead to a reduced level of economic activity and growth. Again we have an estimate based on past experience. Holsen and Waelbroeck (1976) estimated that balance of payments borrowing by ldcs in 1975 and 1976, to a value of $\$ 8$ bn and $\$ 11$ bn respectively, prevented a fall in their GNP by 5.0 and 6.9 per cent in these two years, and thereby contributed 0.4 per cent and 0.6 per cent to the aggregate demand sustaining the GNPs of the developed countries. They added:

It is not usual in analysing business cycle developments to think of developing countries as capable of affecting aggregate demand. This is because they are thought of as adjusting their purchases passively to the level permitted by their foreign exchange earnings. This assumption is not correct any more. Less developed countries' import policies influence demand today in the same way as the US deficit of the late 1960s and early 1970s, and the OPEC balance of payments surplus.

(Holsen and Waelbroeck 1976: 175)

Calculations made for UNCTAD by the University of Pennsylvania using the LINK econometric model of the world economy suggested that an increase of the growth rate by three percentage points in the non-oil producing developing countries would result in an increase of the growth rate by one per cent in the OECD countries (UNCTAD 1976). Since then, more disaggregated analyses on alternative hypotheses have been undertaken by various groups. The results of the simulations undertaken by the US Bureau of Intelligence and Research (1978) summarised in Table 1 , make clear some of the issues.

Table 1

Transfer of $\$ 20$ bn per Year to Non-OPEC Developing Regions, Maintained for Three Years (per cent increase)

\begin{tabular}{lrcc}
\hline Effect on: & \multicolumn{3}{c}{ Year of transfer: } \\
& First & Second & Third \\
World exports (\$) & 2.6 & 2.6 & 2.0 \\
World exports (volume) & 3.0 & 2.8 & 1.8 \\
OECD exports (\$) & 3.1 & 3.1 & 2.3 \\
OECD imports (\$) & 1.3 & 1.6 & 1.5 \\
LDC exports (\$) & 1.4 & 1.7 & 1.4 \\
LDC imports (\$) & 8.4 & 7.1 & 4.6 \\
OECD GNP (real) & 0.5 & 0.6 & 0.4 \\
LDC GNP (real) & 1.7 & 1.8 & 1.5 \\
\hline
\end{tabular}

Source: US Bureau of Intelligence and Research (1978: 3). The final two lines are calculated from data given in later tables of the report.
These simulations consider a transfer of an additional $\$ 20$ bn a year to non-OPEC ldcs sustained for three years. Three ways of financing the transfers were simulated: a) a 'costless' transfer, analogous to transferring profits from the sale of IMF reserves of gold or allocating newly created SDRs to the ldcs. In essence, this corresponds to a Keynesian stimulus to demand which calls into use resources which would otherwise be idle. The results shown in Table 1 correspond to these simulations. Exports and imports in both developed and developing countries would rise considerably. So also would GNP: by roughly 0.5 per cent per year for three years in the industrial countries; by $1 \frac{1}{2}$ per cent, or slightly more, per year for those years in non-OPEC ldcs. The employment impact of such increases was not calculated but, following Okun's rule of thumb, the increase in GNP might be equivalent to a direct increase in employment of perhaps 0.2 per cent or roughly 500,000 jobs throughout the industrial countries.

The other two simulations are based on alternative ways of raising the finance: b) assumes that the $\$ 20$ bn is obtained by diverting government expenditures from domestic goods and services to the transfer programme in each of the 13 industrial countries. The sum involved is roughly 1 per cent of GDP in these countries, so the net effect is, also roughly, just over twice that of increasing oda from the present average level of 0.31 per cent of GNP in the DAC donor countries to the target level of 0.7 per cent of GNP. Simulation c) assumes that the $\$ 20 \mathrm{bn}$ is raised from additional direct taxation.

In both these simulations, the net impact on both developed and developing countries is substantially smaller than that of the first simulation, essentially because the positive impact of the transfers on economic activity in both developed and developing countries is offset by the negative impact of the withdrawal of effective purchasing power in the industrial countries. In the case of the transfer financed by a diversion of government expenditures, the combined effect on the GNP of the developed countries is negative: total GNP with the programme would be something under 0.1 per cent less than without the transfer-though of course GNP in developing countries would be 1.5 per cent higher. In the case of the transfer financed by increasing direct taxation, however, the impact on both developed and developing countries would be positive: for developed countries, an increase of some 0.2 per cent of GNP, and for developing 
countries, about the same amount as in the other simulations.

These simulations offer only a rough guide to the possible effects of transfers of resources, but they can help illuminate some of the issues, particularly the differential impact on the various parties involved.

\section{Structural Change-the Second Objective}

Development, however, means much more than a Keynesian expansion of demand. If a programme of additional transfers is to stimulate more balanced and sustainable growth in the longer run, the transfers must be directed towards adjustment, to deal with structural problems and global imbalance in key sectors such as energy, agriculture, certain sectors of industry and certain, but not all, raw materials and commodities. Imbalances in all these sectors are considerable, and often the outcome of long term trends which have been reinforced over the last few years. It would help to make a start on restructuring if these sectors in developing countries were made the focus for increased investment under the transfer programme.

In more general ways, a massive transfer of resources could greatly assist restructuring. To the extent that a higher level of economic activity was stimulated in the industrialised countries, unemployment would be reduced and thus also one of the main factors which leads to popular and political opposition to imports and restructuring. The link between unemployment and opposition to restructuring and adjustment is worth stressing. More adjustment took place in the 1960s in most industrial countries than has occurred in the last five years. Yet there was relatively little opposition, a comforting contrast with the present, usually attributed at least in part to the lower unemployment and greater economic dynamism of the 1960s.

Taken together, under-utilisation of capacity and the need for restructuring provide the possibility of, and suggest the need for a new international initiative, under which a major increase in transfers from developed to developing countries would be combined with measures to stimulate investment in developing countries in projects or sectors which would ease structural bottlenecks in the medium and longer run. If they were on a reasonable scale, the transfers and investment could provide an important stimulus to higher levels of economic activity in the industrial economies of the West-though their probable scale and timing suggest that any initiative should be judged primarily for its medium term impact than for its short-term countercyclical effects. ${ }^{1}$

Various policy instruments would be available to implement such a programme of transfers:major increases in oda, especially but not only from Germany and Japan, which currently combine relatively low oda performance with very large balance of payments surpluses; additional flows of private finance, possibly stimulated through new institutional mechanisms or a major increase in co-financing; an increase in SDRs, made possible by more ambitious reform of the international monetary system; or a combination of such instruments and measures, old and new, but operated on a much larger scale than at present and adding up to a coordinated, identifiable international initiative.

In my view the critical points for such an initiative to be politically acceptable and economically effective are four. These are:

1) that the programme should combine additional flows of private finance, with at least some reasonable proportion of additional oda. Without this, the poorer countries of the Third World are likely to receive very little benefit, and there will only be limited capacity to stimulate additional investment in activities which are important for development and structural change, but which are only intrinsically or, at first, only marginally viable in commercial terms, such as small scale agriculture, small scale transportation or even energy exploration;

2) that the programme be clearly directed towards stimulating investment of a sort which promotes structural change internationally. The particular sectors to be covered could be for later discussion-though investment (and other related supporting expenditure) to increase Third World production in agriculture, energy, and some sectors of industry and raw material production and processing should certainly qualify. So also would the support of any major regional or global projects and programmes, of the sort which have been proposed for the Third Development Decade and the support of international stockpiling schemes which might form a part of international commodity agreements;

1 Unless used for general balance of payments support it would probably take several years to build up the programme of investment to a sizeable scale. Moreover, est imates suggest that no more than 70 per cent of the OECD multipler effects would take place in the first year. 
3) that responsibility for initiating the programme and controlling its key operations should clearly involve both developed and developing countries on an equitable basis. This is more important than the question of where administrative responsibility for the initiative would rest. As regards administration, it would obviously be desirable to work through existing institutions, if possible relying considerably upon the regional development banks, as a way of securing greater developing country involvement and of strengthening the regional focus;

4) that the initiative should be as substantial as the situation justifies. A programme building up within two to four years to total additional flows of some \$10-20 bn a year would not seem excessive.

The number of voices, official and non-official, calling for such a programme has been growing: President Kreisky in 1976, Cheysson in 1977, the Swedish proposal for a massive programme of transfers in 1978. Over the last 18 months there have been proposals from Nakajima for a Global Inf rastructure Investment Fund; from Senator Javits for a \$25 bn Growth Development Fund; for an OPEC/OECD global stimulation plan and for a 20-year Marshall Plan for the Third World. The ICFTU Review of the World Economic Situation states that there has been 'a growing recognition over the past year of the need for a massive, planned international effort to assist the developing countries-for a new, worldwide "Marshall Plan", as advocated by the ICFTU for some years'. (ICTFU 1978: 23.)

Mr. Roy Jenkins, giving the first Jean Monnet Lecture in October last year, said:

We also need to view the present economic recession in a longer-term perspective. The extent and persistence of unemployment can no longer be seen as an exceptionally low and long bottom to the business cycle. To restore full employment requires a new impulse on a historic scale. We require a new driving force comparable with the major rejuvenations of the past two hundred years; the industrial revolution itself, the onset of the railway age, the impact of Keynes, the need for post-war reconstruction, the spread of what were previously regarded as middle class standards to the mass of the population in the industrial countries. 1 believe that the needs of the Third World have a major part to play here. Two sources of new growth have in the past sometimes come together, the one world-wide and the other regional.

(Jenkins 1977: 9-10)

Yet in spite of these attempts to stimulate serious action on these broad lines, most governments of industrial countries have, to date, been cautious and hesitant. Among the industrial countries, caution has, I believe, been mainly the result of three concerns: the fear of inflation; the uncertainty of the impact on the balance of payments of different countries; the reluctance to consider any initiative which might involve increasing public expenditure.

As indicated at Arusha and Manila, Third World governments have been more open to such proposals-but not without conditions. Third World responses have been particularly sensitive to a strong emphasis on transferring resources in ways which would support international structural change, the inclusion of a component of oda in order that poorer, as well as better-off, developing countries may benefit from the initiative and a broad base of control which will provide for strong participation by developing countries in the management of any such scheme.

The risk of inflation is in my view the most legitimate of such objections. There is no strong evidence to suggest that a stimulus to greater economic activity within the industrial countries would be less inflationary if effected by means of a transfer to developing countries than by a direct expansion of domestic demand. This has led some critics to argue that a major transfer to developing countries must be rejected for the simple reason that industrial countries have obviously been unwilling to undertake major domestic programmes of Keynesian expansion.

In my view it is the general argument that almost any expansion of demand, output and production would be inflationary, that needs to be challenged. The evidence for such a rigid view of a Phillips curve relationship does not exist-and to base policy on the belief that the higher the rate of unemployment the lower will be the rate of inflation, is both over-simplified and misleading. ${ }^{2}$ In contrast one can argue that continuing high unemployment stimulates uncertainty and generates increasing reactions within the organised section of the labour force and among companies with monopolistic power in ways which may result in greater, rather than less, wage-push,

2 See, for example, the comprehensive survey by Santomen and Seaton (1978). 
cost-push and inflationary effects. Moreover, these reactions of ten lead to institutional changes which create further imperfections and rigidities within both labour and other markets, thus adding to inflationary tendencies and mechanisms, built into the economic and social structure over the longer run.

In contrast, clear evidence exists of the favourable effects of structural adjustment and trade links with developing countries on inflation. The 1978 World Development Report showed that textile prices over the past five years had risen by 26 per cent compared with a general rise in the wholesale price index of 66 per cent. A recent Brookings study shows that imports from less developed countries into the United States sell at 16 per cent lower retail prices than comparable domestically produced goods. The OECD itself has recognised that trade with the NICs has provided a 'curb to inflation' within the industrial countries both in the short run and, by encouraging increases in productivity and efficiency, over the longer run.

Except for inflation, the other effects of the programme are matters of policy, not inevitability. The impact on the balance of payments of different industrial countries, for example, will primarily reflect how the size of each country's 'contribution' to the programme compares with the amount of additional exports it gets from the programme. which in turn will primarily reflect the sectors and countries supported and the institutional arrangements governing the use of the transfer funds. All these are matters of policy, which can be adjusted to match the goals and constraints affecting the countries participating in the programme. So also is the form in which the funds are raised and administered.

The need now is for one of the major governments of the industrial powers to give a strong political lead: to recognise the need for a significant international initiative along the lines proposed and to provide the impetus and leadership for it to be converted rapidly into a programme for implementation. The ideas in general terms have already been much debated, but over the years not really engaged because strong political leadership has been lacking. For a proposal now to be seriously developed:

-a time limit should be set for preparing a specific programme; -a clear mandate should be given for an international group or groups to work out the elements of a feasible programme within clear and broad basic guidelines, which recognise the different interests of the various parties involved;

- for both North and South to be involved in whatever formal meetings are required to reach agreement on the proposal.

It is not argued that an initiative on these lines would solve all the major economic problems of the North or the South. In particular, special attention would be needed if the mass of the rural population in the poorer developing countries were to gain much benefit. But a major initiative for restructuring out of recession could provide a more dynamic context in which other long-standing problems could be tackled.

\section{References}

Commission of the European Communities, 1978, Annual Economic Review 1978-1979, (SEC [78] 4033), Brussels, October

Holsen, J. A. and H. L. Waelbroeck, 1976, 'The LDCs and the International Monetary Mechanism', AER Papers and Proceedings, pp. 171-6, May

International Confederation of Free Trades Unions, 1978, Review of the World Economic Situation, Brussels

Jenkins, Roy, 1977, Europe's Present Challenge and Future Opportunity, Commission of the European Communities, (ISEC/B64/77), London

UNCTAD, 1976, Trade Prospects and Capital Needs of Developing Countries 1976-1980, (TD/B/C3/134), Geneva, April

US Bureau of Intelligence and Research, 1978, Financial Transfers from Industrial to Developing Nations: a Re-examination, INR Report no. 1081, Dept. of State, Washington, DC

Santomen, A. M. and J. J. Seaton, 1978, 'The Inflation Unemployment Trade-off: A Critique of the Alternatives', Journal of Economic Literature, pp. 499-544, June 